\title{
Taxonomia de solos desenvolvidos sobre depósitos sedimentares da Formação Solimões no Estado do Acre
}

\author{
Thiago de Andrade Bernini (1); Marcos Gervasio Pereira (2*); Ademir Fontana (3); Lúcia Helena \\ Cunha dos Anjos ( ${ }^{2}$ ); Sebastião Barreiros Calderano (3); Paulo Guilherme Salvador Wadt (4); \\ André Geraldo de Lima Moraes $\left({ }^{2}\right)$; Lauana Lopes dos Santos $\left({ }^{5}\right)$ \\ (1) Instituto Federal de Educação, Ciência e Tecnologia do Rio de Janeiro, Rua José Breves, 550, 27197-000 Pinheiral (RJ), Brasil. \\ (2) Universidade Federal Rural do Rio de Janeiro (UFRRJ), Curso de Pós-Graduação em Agronomia - Ciência do Solo, BR 465, km 7, \\ 23890-000 Seropédica (RJ), Brasil. \\ (3) Embrapa Solos, Rua Jardim Botânico, 1024, 22460-000 Rio de Janeiro (RJ), Brasil. \\ (4) Embrapa Acre, BR 364, km 14, 69908-970, Rio Branco (AC), Brasil. \\ (5) Universidade Federal de Viçosa, Departamento de Solos, Avenida P. H. Rolfs, s/n, 36570-000 Viçosa (MG) Brasil. \\ (*) Autor correspondente: gervasio@ufrri.br
}

Recebido: 25/mar./2012; Aceito: 14/dez./2012

\begin{abstract}
Resumo
Os solos do Estado do Acre na maioria são formados sobre material de origem com grande influência da orogênese Andina, com elevados teores de $\mathrm{Ca}^{2+}, \mathrm{Mg}^{2+}$ e $\mathrm{Al}^{3+}$ concomitantemente, associado às combinações diferenciadas dos valores da CTC, $\mathrm{V}$ e m. O objetivo deste trabalho foi caracterizar e classificar os solos de uma topossequência sobre material sedimentar da Formação Solimões, no município de Feijó, Acre. Foram abertas trincheiras em três pontos de uma topossequência: terço superior (P1), terço médio (P2) e terço inferior (P3). Os solos foram analisados quanto a morfologia, granulometria (areia, silte e argila), complexo sortivo $\left(\mathrm{Ca}^{2+}, \mathrm{Mg}^{2+}, \mathrm{Na}^{+}, \mathrm{K}^{+}\right.$e $\left.\mathrm{Al}^{3+}\right)$, acidez potencial (H+Al), P assimilável, pH (água e $\mathrm{KCl}$ ), superfície específica, ataque sulfúrico (óxidos de Fe, Al, Ti e Si), mineralogia (frações areia, silte e argila). Os solos foram classificados segundo o Sistema Brasileiro de Classificação de Solos (SiBCS, 2006) e apresentada uma proposta de classificação considerando as peculiaridades do solos da região. Os solos têm baixo grau de desenvolvimento pedogenético, com minerais da fração argila de alta atividade, além da presença de minerais primários, como feldspatos e plagioclásios, nas frações areia e silte. Os solos foram classificados segundo o SiBCS atual como Argissolo Vermelho Álitico plíntico (P1), Argissolo Acinzentado Distrófico plíntico (P2) e Cambissolo Háplico Ta Eutrófico típico (P3).
\end{abstract}

Palavras-chave: Amazônia Ocidental, pedogênese, classificação, SiBCS.

\section{Taxonomy of soils developed under sedimentary deposits from Solimões Formation in Acre state, Brazil}

\section{Abstract}

The soils from the State of Acre (Brazil) are mostly formed under parent material with influence of Andean orogeny, showing high $\mathrm{Ca}^{2+}, \mathrm{Mg}^{2+}$ and $\mathrm{Al}^{3+}$ contents concomitantly associated with different combinations of $\mathrm{CEC}, \mathrm{V}$ and $\mathrm{m}$ values. This study aimed to characterize and classify soils of a topossequence under sedimentary material from Solimões Formation, in the county of Feijó, State of Acre, Brazil. Trenches were opened in three points on a topossequence: shoulder (P1), backslope (P2) and footslope (P3). The soils were analyzed by morphology, particle size (sand, silt and clay), exchangeable cations (Ca' ${ }^{2+}, \mathrm{Mg}^{2+}$, $\mathrm{Na}^{+}, \mathrm{K}^{+}$and $\mathrm{Al}^{3+}$ ), potential acidity $\left(\mathrm{H}^{+} \mathrm{Al}\right), \mathrm{P}$ assimilable, $\mathrm{pH}$ (water and $\left.\mathrm{KCl}\right)$, specific surface, sulfuric attack $(\mathrm{Fe}, \mathrm{Al}$, Ti and $\mathrm{Si}$ oxides), and mineralogy (sand, silt and clay). The soils were classified according to the Brazilian System of Soil Classification (SiBCS, 2006) and a classification considering the peculiarities of the soils was proposed. The soils have a low degree of pedogenetic development, with minerals of high activity in the clay fraction, and the presence of primary minerals such as feldspar and plagioclase in the sand and silt fractions. The soils were classified according to the current SiBCS as Argissolo Vermelho Álitico plíntico (P1), Argissolo Acinzentado Distrófico plíntico (P2) e Cambissolo Háplico Ta Eutrófico típico (P3).

Key words: Western Amazon, pedogenesis, classification, SiBCS. 


\section{INTRODUÇÃO}

Situado no extremo sudoeste da Região Norte do Brasil, na Amazônia brasileira, o Estado do Acre limita-se ao norte com o Estado do Amazonas, a leste com o Estado de Rondônia, a sudeste com a Bolívia e ao sul e oeste com o Peru. O Estado do Acre apresenta pela divisão morfoestrutural a Depressão Amazônica, Planalto Rebaixado e Planície Amazônica (WADT, 2002).

No Estado do Acre ocorrem várias formaçóes geológicas, sendo a Formação Solimôes a mais significativa, cobrindo quase toda a regiáo interfluvial. Depositada no fim do Mioceno e o início do Plioceno é a mais significativa e representa a maior do Estado (ACRE, 2006; WestaWAy, 2006). Nesta formaçáo geológica são observadas estratificaçôes plano-paralelas e cruzadas tabulares e acanaladas de pequena, média e grande amplitudes, cuja sedimentação está associada à orogênese dos Andes e à subsidência geral da bacia, com afundamentos e soerguimentos de intensidade variável, resultantes da reativação de antigas falhas (Cavalcante, 2006).

A Formação Solimóes constitui-se essencialmente de argilitos e siltitos finamente laminados e maciços, contendo lentes de linhito e turfa, concreçôes carbonáticas e gipsíferas, além de quantidades menores de sedimentos arenosos. Essa diversificação implica grande variaçâo de classes de solos, na variabilidade quanto à suscetibilidade à erosão, no seu ciclo hidrológico e em sua vegetação natural (CAVALCANTE, 2006).

No Estado, são observados solos pouco intemperizados como os Vertissolos, Cambissolos, Luvissolos e Nitossolos, os quais se caracterizam pela presença de caulinita associada a minerais do grupo das esmectitas, vermiculitas e cloritas (Volkoff et al., 1989; Lima et al., 2006), ao lado de solos mais intemperizados, como Plintossolos, Argissolos e Latossolos (WADT, 2004).

Pelas unidades morfoestruturais, na Planície Amazônica, observam-se os solos característicos das várzeas como os Gleissolos e Neossolos Flúvicos, no Planalto Rebaixado, que compreende a regiāo do extremo oeste e a regiáo leste e sudeste do Estado, onde predominam os Argissolos, os Plintossolos e alguns Latossolos. $\mathrm{Na}$ Depressão Amazônica, que compreende a maior parte do Estado, principalmente a regiáo central, localizam-se os Cambissolos e Argissolos (WADT, 2002).

A presença de quantidades expressivas de argilominerais de estrutura 2:1, teores elevados de silte e alumínio, associados a teores também elevados de cálcio e magnésio trocáveis, contribuem para os elevados valores na soma de bases e da capacidade de troca catiônica dos solos (Volkoff et al., 1989; Coelho et al. 2005; Lima et al., 2006). Pela combinação de elevados teores de bases trocáveis, associados a também elevados teores de alumínio trocável, observa-se uma limitação na classificação taxonômica do Sistema Brasileiro de Classificação de Solos (EMBRAPA, 2006), indicando a necessidade de revisão dos critérios e a apresentação de proposta de classificação mais apropriada aos solos da região estudada.

A partir do exposto, o presente trabalho teve como objetivo caracterizar e classificar os solos de uma topossequência sobre material sedimentar da Formação Solimôes, no município de Feijó, Acre.

\section{MATERIAL E MÉTODOS}

\section{Área de estudo}

A área de estudo está localizada no município de Feijó (S 8 31.985 e W 69 59.184), situado na regional do Tarauacá e Envira, Estado do Acre (Figura 1).

A unidade geomorfológica compreende a Depressão do Juruá-Iaco, que compóe a unidade morfoestrutural da Depressão Amazônica, caracterizada por uma feição colinosa e relevo ondulado, atingindo $250 \mathrm{~m}$ de altitude. O clima pela classificação de Köppen é Aw, definido como tropical com estaçâo seca no inverno e Am, tropical chuvoso (BRASIL, 1976). Na região, observam-se altas temperaturas (média anual de $24,5^{\circ} \mathrm{C}$ ) e altos índices pluviométricos (médias anuais de $2.000 \mathrm{~mm}$ ), com duas estaçốes bem definidas: período chuvoso, de novembro a abril e menos chuvoso, de junho a setembro (ACRE, 2006).

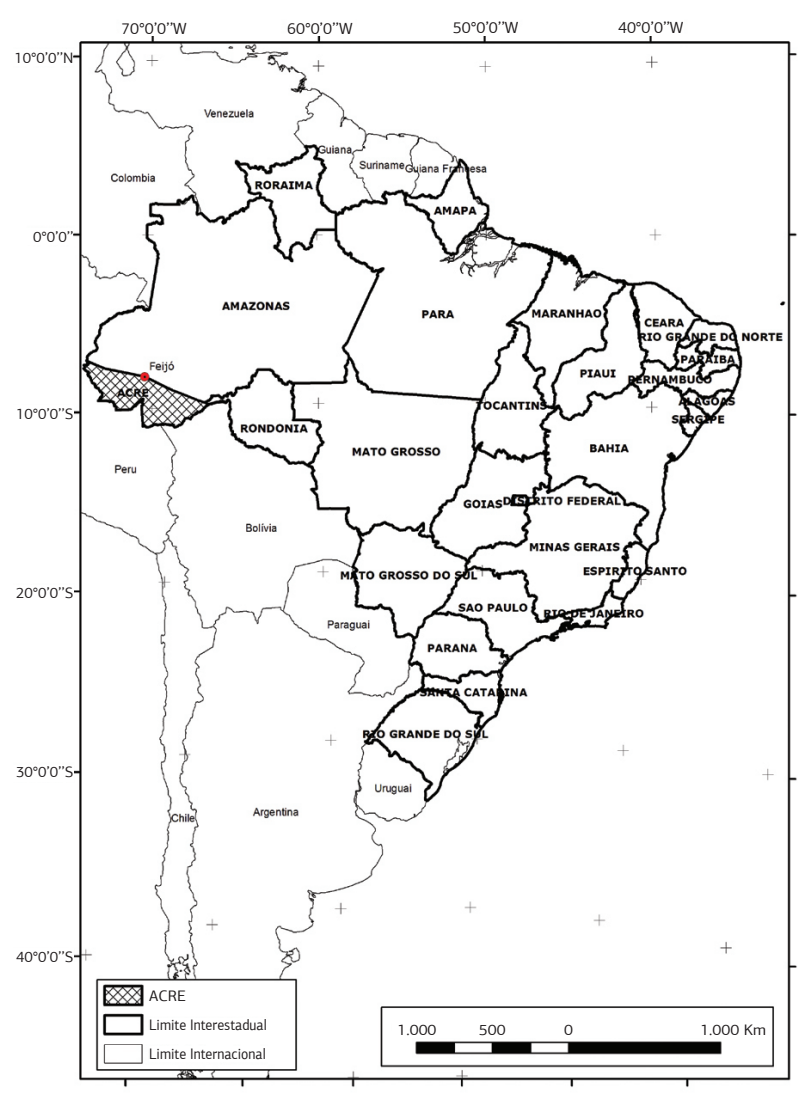

Figura 1. Localização da área de estudo no município de Feijó, Estado do Acre, Brasil. 
A geologia na topossequência estudada pertence à Formação Solimôes, com sedimentos pelíticos e psamíticos de depósitos Cenozóicos (Cavalcante, 2006). A vegetação atual é representada por uma floresta aberta com palmeiras, bambus e cipós.

$\mathrm{Na}$ área, foram abertas trincheiras em três pontos distintos de uma topossequência: terço superior (P1), terço médio (P2) e terço inferior da elevação (P3), com distância aproximada de $60 \mathrm{~m}$ entre os perfis. Foi realizada a descrição geral e morfológica dos perfis de solo, segundo o Manual de Descriçáo e Coleta de Solo no Campo (SAntos et al., 2005), seguindo com a coleta de amostras de cada horizonte para as análises físicas, químicas e mineralógicas.

\section{Análises laboratoriais}

A análise granulométrica foi realizada em terra fina seca ao ar (TFSA), pelo método da dispersão por agitação lenta, usando $\mathrm{NaOH} 0,1 \mathrm{~mol} \mathrm{~L}^{-1}$. O teor de argila total foi determinado na suspensão, pelo método da pipeta (DAY, 1965). As fraçóes areia grossa e areia fina foram separadas por tamisaçáo, em peneiras de malhas 0,2 e $0,053 \mathrm{~mm}$ respectivamente. O silte foi obtido por diferença. Os teores de argila dispersa em água foram obtidos pelo método semelhante ao utilizado para a determinação da argila total, usando apenas água destilada.

Os íons $\mathrm{Ca}^{2+}, \mathrm{Mg}^{2+}$ e $\mathrm{Al}^{3+}$ foram extraídos com solução de $\mathrm{KCl} \mathrm{1,0} \mathrm{mol} \mathrm{L-1}$. Os teores de $\mathrm{Ca}^{2+}$ e $\mathrm{Mg}^{2}$ foram determinados por titulometria com solução de EDTA $0,0125 \mathrm{~mol} \mathrm{~L}^{-1}$ e o $\mathrm{Al}^{3+}$ por titulometria com $\mathrm{NaOH} 0,025 \mathrm{~mol} \mathrm{~L}^{-1}$. O pH em água e em $\mathrm{KCl}$ (peso $1: 2,5)$ foi determinado por meio de potenciômetro.

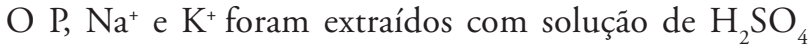
$0,0125 \mathrm{~mol} \mathrm{~L}^{-1}+\mathrm{HCl} 0,05 \mathrm{~mol} \mathrm{~L}^{-1} ; \mathrm{Na}^{+}$e K $\mathrm{K}^{+}$por fotometria de chama e o $\mathrm{P}$ por colorimetria. A acidez potencial $(\mathrm{H}+\mathrm{Al})$ foi extraída com solução de $\mathrm{Ca}\left(\mathrm{C}_{2} \mathrm{H}_{3} \mathrm{O}_{2}\right)_{2}$ $0,5 \mathrm{~mol} \mathrm{~L}^{-1}$ a $\mathrm{pH}$ 7,0 e determinada por titulometria com $\mathrm{NaOH} 0,025 \mathrm{~mol} \mathrm{~L}^{-1}$. Foram calculadas a soma de bases trocáveis $(\mathrm{SB})$, capacidade de troca catiônica a $\mathrm{pH}$ 7,0 (CTC do solo), CTC da argila (CTC/argila x 1000), saturação por bases (V) e saturação por alumínio (m). Os procedimentos acima foram realizados de acordo com EMBRAPA (1997).

A superfície específica foi determinada na TFSA previamente moída e passada em peneira de 60 meshes. A adsorção foi medida pelo uso do etileno glicol monometil éter (EMGE) (CARTER et al., 1965; Heilman et al., 1965) e modificaçóes de Cihaek e Bremmer (1979). Foi pesado $1,0 \mathrm{~g}$ de amostra e adicionado 3,0 mL de EMGE, seguido com vácuo em dessecador com $\mathrm{CaCl}_{2}$, efetuando-se pesagens a intervalos pré-estabelecidos, até obtenção de massa constante. A superfície específica foi calculada pela

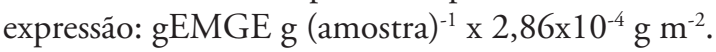

$\mathrm{O}$ ataque sulfúrico foi realizado na fraçáo argila e constituiu a adição de uma soluçãa de $\mathrm{H}_{2} \mathrm{SO}_{4}$ (1:1) e fervura por meia hora sob refluxo e posterior resfriamento e filtragem. No filtrado foram determinados teores de Fe, Al e Ti, e no resíduo, o Si (EMBRAPA, 1997), sendo os resultados expressos nos teores de $\mathrm{SiO}_{2}, \mathrm{Al}_{2} \mathrm{O}_{3}, \mathrm{Fe}_{2} \mathrm{O}_{3}$, $\mathrm{TiO}_{2}$; a partir destes, foram calculadas as relaçôes moleculares ki $\left(\mathrm{SiO}_{2} / \mathrm{Al}_{2} \mathrm{O}_{3}\right)$ e $\mathrm{kr}\left(\mathrm{SiO}_{2} / \mathrm{Al}_{2} \mathrm{O}_{3}, \mathrm{Fe}_{2} \mathrm{O}_{3}\right)$.

$\mathrm{A}$ análise mineralógica da areia e silte foi realizada após a dispersão e sedimentação das fraçôes com $\mathrm{NaOH} 1 \mathrm{~mol} \mathrm{~L}^{-1}$, sem eliminação de óxidos de ferro (EMBRAPA, 1997). As amostras das fraçóes areia e silte foram previamente trituradas em moinho de bolas para obtenção do pó cristalino. A avalição da composição mineralógica foi realizada por difração de raio-X (DRX), em pó não orientado, com a utilização de um difratômetro Bruker AXS, modelo D8 Advance, empregando-se radiação de $\mathrm{K} \alpha$ de $\lambda 0,015405 \mathrm{~nm}$, produzida por tubo de cobre, $40 \mathrm{kv}$ e $40 \mathrm{~mA}$, com amplitude de varredura igual a ${ }^{\circ} 2 \theta$ por minuto $\left(0,04^{\circ} \mathrm{s}^{-1}\right)$. Os difratogramas foram gerados no programa Xpowder Ver. 2004.04.67 PRO para identificar os minerais e estimar suas proporções.

A fração argila foi obtida por dispersão e agitação com $\mathrm{NaOH} 1 \mathrm{~mol} \mathrm{~L}^{-1}$, sendo as amostras analisadas em condição natural e sob os seguintes tratamentos: desferrificaçáo por citrato-bicarbonato-ditionito de sódio (MeHra e JACKSON, 1960); saturação com potássio e aquecimento por duas horas nas temperaturas de 110,350 e $550^{\circ} \mathrm{C}$; saturação com magnésio e solvatação com etileno glicol (EMBRAPA, 1997; Calderano et al., 2009). As lâminas foram montadas de forma orientada, pelo método do esfregaço. As análises foram realizadas em difratômetro Rigaku, modelo Miniflex II, empregando-se radiaçáo de $\mathrm{K} \alpha$ de $\lambda 0,154 \mathrm{~nm}$, produzida por tubo de cobre, $30 \mathrm{kv}$ e $15 \mathrm{~mA}$, com amplitude de varredura igual a $2^{\circ}$ a $45^{\circ}(2 \theta)$, constante de tempo de 1 segundo e passo de $0,050^{\circ}$. Os difratogramas foram confeccionados usando o programa Microcal Origin 6.0. Os difratogramas foram interpretados segundo as tabelas e critérios de Thorez (1976), Brindley e Brown (1984), Moore e Reynolds (1997). A grafia dos nomes dos minerais está de acordo com Branco (1987).

Para as amostras da fração argila com indicação de presença de minerais 2:1, além dos tratamentos acima mencionados, foram feitos os pré-tratamentos: aquecimento a $550^{\circ} \mathrm{C}$, saturação com etilenoglicol e dimetilsulfóxido, com posterior irradiação pelo raio-X. A apresentação dos difratogramas consta com a mostra não tratada (Am.total); amostra desferrificada e saturada com magnésio $(\mathrm{Mg})$ e, posteriormente, solvatada com etileno glicol (MgEG); amostra desferrificada e saturada com potássio, com varreduras executadas à temperatura ambiente (K25) e, após aquecimento, nas temperaturas assinaladas (K350 e K550). 
A partir dos atributos da morfológicos, físicos, químicos e mineralógicos, os solos foram classificados taxonomicamente, segundo o Sistema Brasileiro de Classificação de Solos (EMBRAPA, 2006).

\section{RESULTADOS E DISCUSSÃO}

\section{Atributos morfológicos}

Os dados morfológicos demonstram que os horizontes superficiais (A e AB) possuem espessuras variadas, chegando a $21 \mathrm{~cm}$ (Tabela 1). Os horizontes subsuperficiais (Bt) dos perfis P1 e P2 são mais espessos, com valores de, respectivamente, 133 e $129 \mathrm{~cm}$, enquanto o perfil P3 possui apenas $48 \mathrm{~cm}$ de horizonte $\mathrm{Bi}$, ocorrendo o horizonte $\mathrm{Cv}$ a $66 \mathrm{~cm}$ de profundidade. Foi observado padrão semelhante de espessura do horizonte A moderado (6 a
$21 \mathrm{~cm}$ ), na região de Benjamin Constant, Alto Solimôes, Estado do Amazonas por Coelho et al. (2005), em solos com estágio incipiente de desenvolvimento como os Cambissolos e Gleissolos.

Para a cor dos solos, verifica-se nos horizontes A cores escuras e matizes 5YR, 7,5YR e 10YR, com valor 3 e croma entre 1 e 2 (Tabela 1). As cores escuras, com baixo valor e croma dos solos são reflexos da presença da matéria orgânica, que se concentra na parte superficial dos perfis. Nos horizontes subsuperficiais, as cores predominantes foram brunadas e/ou acinzentadas, além das cores avermelhadas no perfil P1, com valor aumentando em profundidade e croma entre 1 e 4 . Nesses horizontes, evidencia-se a relação entre as cores acinzentadas e a drenagem dos perfis, que foram moderadamente drenados (P1 e P2) e imperfeitamente drenado (P3), caracterizando um ambiente com restriçôes de permeabilidade, independente da posição que se encontram na topossequência.

Tabela 1. Atributos morfológicos dos perfis de solo da topossequência estudada no município de Feijó, Estado do Acre

\begin{tabular}{|c|c|c|c|c|c|c|}
\hline \multirow{2}{*}{ Hor. } & \multirow{2}{*}{$\begin{array}{l}\text { Prof. } \\
\mathrm{cm}\end{array}$} & \multicolumn{2}{|c|}{ Cor (úmida) } & \multirow{2}{*}{$\begin{array}{c}\text { Cor } \\
\text { Nomenclatura }\end{array}$} & \multirow{2}{*}{ Textura } & \multirow{2}{*}{ Estrutura } \\
\hline & & Matriz & Mosqueado & & & \\
\hline \multicolumn{7}{|c|}{ Perfil 1} \\
\hline A & $0-3$ & $7,5 Y R 3 / 2$ & & Bruno-escuro & Franco-siltosa & mod. gr. gran. \\
\hline AB1 & $3-15$ & 2,5YR $5 / 2$ & & Vermelho-acinzentado & Franca & mod. peq. bl. sub. \\
\hline AB2 & $15-26$ & 2,5 YR $5 / 2$ & & Vermelho-acinzentado & Franca & mod. peq. bl. sub. \\
\hline BA & $26-40$ & 2,5YR 5/4 & & Bruno-avermelhado & Franco-siltosa & mod. peq. bl. ang. \\
\hline $2 \mathrm{Bt}$ & $40-88$ & $2,5 Y R \quad 4 / 4$ & & Bruno-avermelhado & Muito argilosa & mod. méd. bl. ang. \\
\hline 2Btf & $88-148+$ & 10YR 6/2 & $\begin{array}{l}2,5 \text { YR } 3 / 6 \text { ab. } \\
\text { méd. pro. }\end{array}$ & Cinzento-brunado-claro & Argila & mod. méd. bl. ang \\
\hline \multicolumn{7}{|c|}{ Perfil 2} \\
\hline A & $0-5$ & $7,5 Y R 3 / 2$ & & Bruno-escuro & $\begin{array}{l}\text { Franco-argilo- } \\
\text { arenosa }\end{array}$ & mod. gr. gran. \\
\hline$A B$ & $5-11$ & $7,5 Y R 4 / 4$ & & Bruno & $\begin{array}{l}\text { Franco-argilo- } \\
\text { arenosa }\end{array}$ & fr. peq. bl. ang. \\
\hline BA & $11-21$ & $5 Y R 3 / 3$ & & $\begin{array}{l}\text { Bruno-avermelhado- } \\
\text { escuro }\end{array}$ & $\begin{array}{l}\text { Franco-argilo- } \\
\text { arenosa }\end{array}$ & mod. peq. bl. sub. \\
\hline Bt1 & $21-29$ & 10YR $4 / 3$ & & Bruno & $\begin{array}{l}\text { Franco-argilo- } \\
\text { arenosa }\end{array}$ & mod. méd. bl. ang. \\
\hline Bt2 & $29-41$ & 10YR $6 / 2$ & $\begin{array}{l}\text { 2,5YR } 5 / 4 \text { e } 3 / 6 \\
\text { ab. peq. pro. }\end{array}$ & $\begin{array}{l}\text { Cinzento-brunado- } \\
\text { claro }\end{array}$ & Argila & mod. méd. bl. ang. \\
\hline Btf1 & $41-54$ & 10YR $6 / 2$ & $\begin{array}{l}\text { 2,5YR 3/6 } \\
\text { ab. peq. pro. }\end{array}$ & $\begin{array}{l}\text { Cinzento-brunado- } \\
\text { claro }\end{array}$ & Muito argilosa & fo. méd. bl. ang. \\
\hline Btf2 & $54-102$ & 10YR 7/1 & 2,5YR 4/4 & Cinzento-claro & Argila & fo. méd. bl. ang. \\
\hline C & $102-140+$ & 10YR $7 / 1$ & $\begin{array}{l}\text { 5YR } 4 / 6 \\
\text { ab. peq. pro. }\end{array}$ & Cinzento-claro & Argilo-siltosa & mod. gr. bl. ang. \\
\hline \multicolumn{7}{|c|}{ Perfil 3} \\
\hline A & $0-10$ & 10YR 3/1 & & Cinzento muito escuro & Argilo-siltosa & mod. gr. gran. \\
\hline$A B$ & $10-18$ & 10YR $4 / 2$ & & $\begin{array}{l}\text { Bruno-acinzentado- } \\
\text { escuro }\end{array}$ & Franco argilosa & fo. méd. bl. ang. \\
\hline BA & $18-35$ & 10YR $4 / 2$ & & $\begin{array}{l}\text { Bruno-acinzentado- } \\
\text { escuro }\end{array}$ & Argila & fo. méd. bl. ang. \\
\hline $\mathrm{Bi}$ & $35-66$ & 10YR $7 / 1$ & 5YR 4/6 & Cinzento-claro & Argilo-siltosa & mod. méd. bl. ang. \\
\hline Cv1 & $66-114$ & 10YR 7/1 & $\begin{array}{c}\text { 5YR 4/6 } \\
\text { co. peq. pro. }\end{array}$ & Cinzento-claro & Argila & maciça \\
\hline Cv2 & $114-150+$ & 10YR $7 / 2$ & $\begin{array}{c}5 Y R 6 / 2,3 / 2 \text { e } \\
5 / 4 \text { co. peq. pro. }\end{array}$ & Cinzento-claro & Argila & maciça \\
\hline
\end{tabular}

Hor.: horizonte; Prof.: profundidade; co.: comum; ab.: abundante; peq.: pequeno; méd.: médio; gr.: grande; pro.: proeminente; fr.: fraca; mod.: moderada; fo.: forte; gran.: granular; bl.: blocos; ang.: angulares; sub.: subangulares. 
Também foram observados mosqueados em todos os perfis, com cores predominantemente avermelhadas e de quantidade abundante, sendo observados em maior expressão nos horizontes Cv1 e Cv2 do perfil P3 (Tabela 1).

Além dos processos que ocorrem in situ, a cor dos solos da região representa uma característica herdada, devido à proximidade e jovialidade do material de origem oriundo da cordilheira Andina. Destaca-se o predomínio de cores brunadas e acinzentadas, ocorrendo cores mais escuras no horizonte $\mathrm{A}$, em virtude da matéria orgânica, e cores mais acinzentadas e caráter plíntico em subsuperfície, evidenciando drenagem deficiente, o que foi atribuída à presença de argilas de alta atividade e a baixa permeabilidade dos substratos.

Ainda, em solos da Formação Solimóes, no município de Rio Branco, Araújo et al. (2004) observaram evidências de restrição de drenagem, destacando-se as amostras policrômicas, descritas nos horizontes $\mathrm{B}$ e C, com cores mosqueadas e variegadas, decorrentes da segregação de ferro e manganês em ambiente redutor.

Adicionalmente, a natureza do material de origem e mineralogia contribui para a estruturaçáo dos solos de forma diferenciada, tendo os horizontes A estrutura granular, de tamanho grande e de desenvolvimento moderado (Tabela 1). Nos horizontes B foram observados blocos angulares e nos horizontes de transição BA, blocos subangulares. Para o grau de desenvolvimento verificou-se variaçáo de moderada a forte e tamanho de pequeno a grande. Os horizontes $\mathrm{C}$ são de estrutura maciça, como reflexo da baixa permeabilidade, que mantém o horizonte com alta umidade, favorecendo a coesão das partículas e impedindo a formação da estrutura com agregação.

\section{Atributos físicos}

A composição granulométrica representa alta variação dentro e entre perfis, a qual pode ser observada primeiramente pela análise das relaçóes silte/argila e areia fina/areia grossa (Tabela 2), destacando a heterogeneidade do material de origem colúvio-aluvionar depositado no Holoceno. Ainda, os altos teores de argila dispersa em água e consequentemente os baixos valores do grau de floculaçáo destacam a jovialidade pedológica dos solos (Tabela 2).

Contudo, é possível observar aumento dos teores de argila em profundidade, iniciando a $26 \mathrm{~cm}$ no perfil $\mathrm{P} 1$, a $11 \mathrm{~cm}$ no perfil P2 e a $18 \mathrm{~cm}$ no perfil P3 (Tabela 2).

$\mathrm{O}$ aumento em profundidade dos teores de argila pode ser observado pela relaçáo textural $(\mathrm{B} / \mathrm{A})$, confirmando nos perfis $\mathrm{P} 1$ e $\mathrm{P} 2$ gradiente textural, com valores de 2,4 e 1,7 respectivamente (EMBRAPA, 2006).

Ainda se destacam os altos teores de areia fina no perfil P2 até o horizonte Bt1, chegando a mais de $500 \mathrm{~g} \mathrm{~kg}^{-1} \mathrm{e}$ os altos teores de silte no perfil P1 até o horizonte BA, que

Tabela 2. Atributos físicos dos perfis de solo da topossequência estudada no município de Feijó, Estado do Acre

\begin{tabular}{|c|c|c|c|c|c|c|c|c|c|c|}
\hline \multirow{3}{*}{ Hor. } & \multirow{2}{*}{ Prof. } & \multicolumn{4}{|c|}{ Granulometria } & \multirow{2}{*}{ ADA } & \multirow{2}{*}{ GF } & \multirow{2}{*}{ Silte/Argila } & \multirow{2}{*}{ AF/AG } & \multirow{2}{*}{ S.e. } \\
\hline & & Areia grossa & Areia fina & Silte & Argila & & & & & \\
\hline & $\mathrm{cm}$ & & $\mathrm{g} \mathrm{kg}^{-1}$ & & & & $\%$ & & & $\mathbf{m}^{2} \mathbf{g}^{-1}$ \\
\hline \multicolumn{11}{|c|}{ Perfil 1} \\
\hline A & $0-3$ & 58 & 162 & 593 & 187 & 41 & 78 & 3,2 & 2,8 & \\
\hline$A B 1$ & $3-15$ & 27 & 289 & 453 & 232 & 95 & 59 & 2,0 & 10,7 & \\
\hline AB2 & $15-26$ & 15 & 283 & 463 & 239 & 197 & 17 & 1,9 & 18,9 & \\
\hline BA & $26-40$ & 10 & 215 & 388 & 387 & 153 & 60 & 1,0 & 21,5 & \\
\hline $2 \mathrm{Bt}$ & $40-88$ & 7 & 92 & 230 & 671 & 355 & 47 & 0,3 & 13,1 & 200 \\
\hline 2Btf & $88-148+$ & 6 & 137 & 310 & 548 & 293 & 47 & 0,6 & 22,8 & \\
\hline \multicolumn{11}{|c|}{ Perfil 2} \\
\hline A & $0-5$ & 42 & 509 & 200 & 248 & 78 & 69 & 0,8 & 12,1 & \\
\hline$A B$ & $5-11$ & 11 & 575 & 190 & 224 & 90 & 60 & 0,8 & 52,3 & \\
\hline BA & $11-21$ & 12 & 528 & 178 & 282 & 141 & 50 & 0,6 & 44,0 & \\
\hline Bt1 & $21-29$ & 4 & 462 & 187 & 348 & 201 & 42 & 0,5 & 115,5 & \\
\hline Bt2 & $29-41$ & 3 & 237 & 163 & 597 & 376 & 37 & 0,3 & 79,0 & \\
\hline Btf1 & $41-54$ & 6 & 174 & 210 & 611 & 455 & 26 & 0,3 & 29,0 & 274 \\
\hline Btf2 & 54-102 & 17 & 145 & 292 & 546 & 444 & 19 & 0,5 & 8,5 & \\
\hline C & $102-140+$ & 35 & 99 & 406 & 460 & 405 & 12 & 0,9 & 2,8 & \\
\hline \multicolumn{11}{|c|}{ Perfil 3} \\
\hline A & $0-10$ & 15 & 171 & 410 & 404 & 168 & 58 & 1,0 & 4,0 & \\
\hline$A B$ & $10-18$ & 11 & 268 & 338 & 383 & 174 & 55 & 0,9 & 6,3 & \\
\hline BA & $18-35$ & 9 & 172 & 366 & 454 & 279 & 38 & 0,8 & 11,0 & \\
\hline $\mathrm{Bi}$ & $35-66$ & 4 & 42 & 448 & 506 & 406 & 20 & 0,9 & 3,7 & 217 \\
\hline Cv1 & $66-114$ & 16 & 58 & 329 & 597 & 374 & 37 & 0,6 & 6,8 & \\
\hline Cv2 & 114-150+ & 48 & 64 & 329 & 560 & 361 & 35 & 0,6 & 4,8 & 266 \\
\hline
\end{tabular}

Hor.: horizonte; Prof.: profundidade; ADA: argila dispersa em água; GF: grau de floculaçáo; AF/AG: relaçấo areia fina/ areia grossa; S.e.: superfície específica. 
pode ser observado também pelos altos valores da relação silte/argila (Tabela 2). Os altos teores de silte no perfil P1 reportam a mudança de material de origem, conforme destacado na nomenclatura e sequência de horizontes e ainda a jovialidade dos sedimentos depositados.

Os valores de superfície específica dos horizontes subsuperficiais $2 \mathrm{Bt}, \mathrm{Btf} 1, \mathrm{Bi}$ e $\mathrm{CV} 2$ são superiores a $200 \mathrm{~m}^{2} \mathrm{~g}^{-1}$ (Tabela 2). Estes valores caracterizam o material de origem dos solos da regiáo com presença de minerais de argila com elevada superfície específica e com reflexo na capacidade de troca catiônica. Em estudo com o material de origem de alguns solos do Acre, Volkoff et al. (1989) identificaram materiais ricos em montmorilonita, com presença variável de illita e de vermiculita e baixos teores de caulinita.

\section{Atributos químicos}

Nos solos estudados, os valores de $\mathrm{pH}$ (água) estão entre 4,4 (BA, perfil P1) e 6,1 (Cv2, perfil P3), sendo estes superiores aos valores de $\mathrm{pH}(\mathrm{KCl})$, entre 3,5 (Bt, perfil $\mathrm{P} 2$ ) e 5,7 (A, perfil P1) (Tabela 3). Todos os valores de $\Delta \mathrm{pH}$ foram negativos, destacando os horizontes subsuperficiais, chegando a -2,0 no Cv1 do perfil P3. Os valores de $\Delta \mathrm{pH}$ negativos indicam grande quantidade de cargas líquidas negativas e reflexo na maior capacidade de troca de cátions dos solos. Lima et al. (2006) verificaram valores de $\Delta \mathrm{pH}$ negativos, indicando predomínio de carga superficial líquida negativa em todos os solos de uma topossequência da bacia sedimentar do Alto Solimóes, no Estado do Acre.

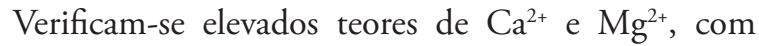
variações no perfil e entre os perfis, com alternância do predomínio de $\mathrm{Ca}^{2+}$ ou $\mathrm{Mg}^{2+}$, sendo estes os cátions predominantes na soma de bases trocáveis (SB), com baixos valores de $\mathrm{K}^{+}$e $\mathrm{Na}^{+}$(Tabela 3 ). No perfil P1, os elevados teores de $\mathrm{Ca}^{2+}$ em superfície são indicativos da mudança de material de origem. No perfil $\mathrm{P} 2$, o aumento relativo do $\mathrm{Mg}^{2+}$ nos horizontes subsuperficiais refere-se à migração pelo perfil de solo, devido à maior mobilidade deste íon em detrimento ao $\mathrm{Ca}^{2+}$, enquanto no perfil $\mathrm{P} 3$ observa-se o predomínio de $\mathrm{Ca}^{2+}$ (Tabela 3 ).

Nos horizontes com predomínio de $\mathrm{Ca}^{2+}$ foram observados valores de saturação por bases $(\mathrm{V})$ maiores que $50 \%$, e naqueles com predomínio de $\mathrm{Mg}^{2+}$, os valores de $\mathrm{V}$ foram menores que $50 \%$. Nestes últimos, os baixos teores de $\mathrm{Mg}^{2+}$ estão associados a teores de $\mathrm{Al}^{3+}$ mais elevados, chegando a $15,1 \mathrm{cmol}_{\mathrm{c}} \mathrm{kg}^{-1}$ no perfil P2, e valores de saturação por alumínio $(\mathrm{m})$ maiores que $50 \%$. Em todos os horizontes do perfil $\mathrm{P} 3$ os valores de $\mathrm{V}$ foram maiores que $50 \%$, indicando solo eutrófico, mesmo com altos teores de $\mathrm{Al}^{3+}$ (Tabela 3).

Tabela 3. Atributos químicos dos perfis de solo da topossequência estudada no município de Feijó, Estado do Acre

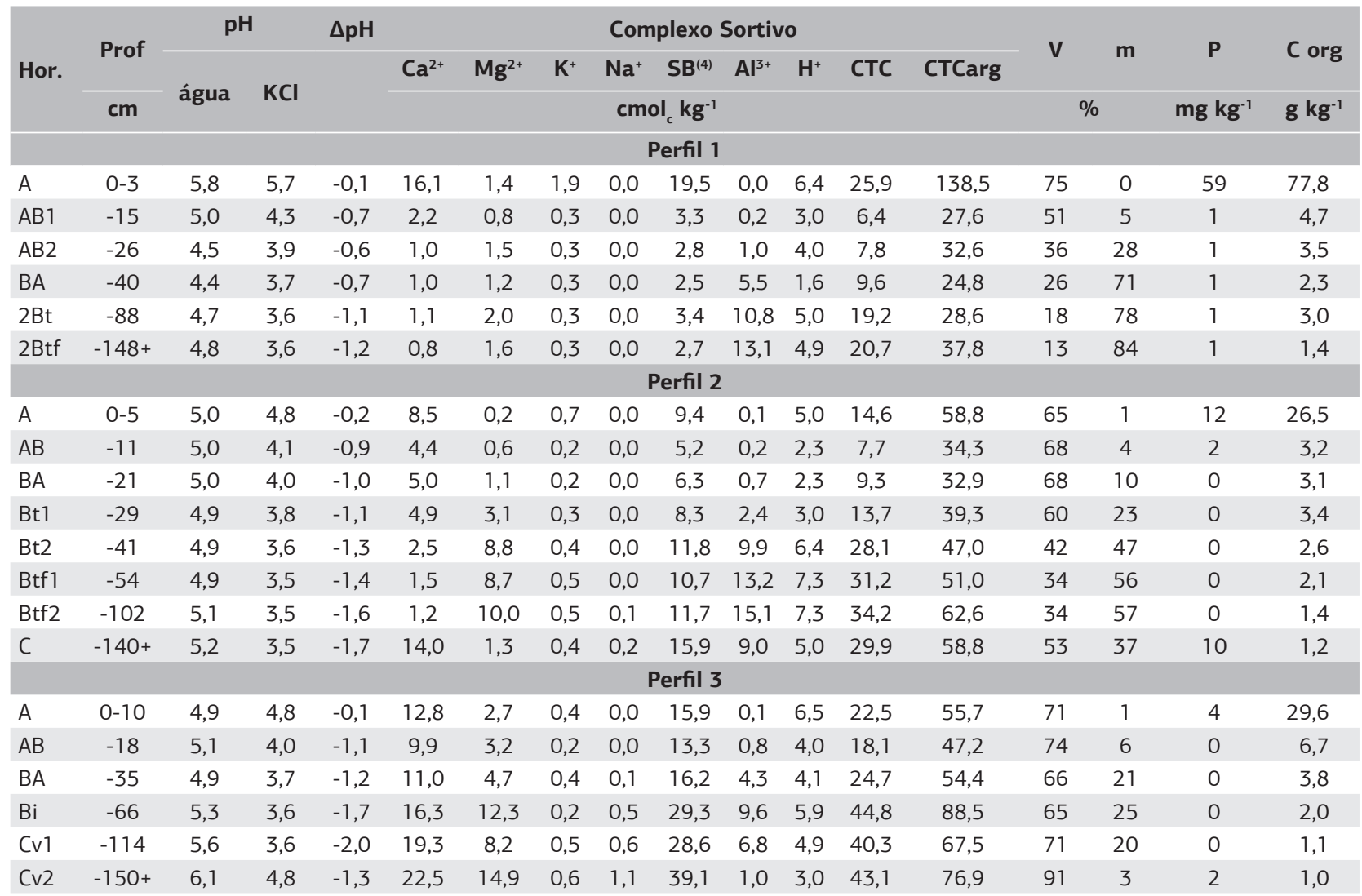

Hor.: horizonte; Prof.: profundidade; $\Delta \mathrm{pH}$ po $\mathrm{pH} \mathrm{KCl} \mathrm{-} \mathrm{pHágua;} \mathrm{SB:} \mathrm{soma} \mathrm{de} \mathrm{bases} \mathrm{trocáveis;} \mathrm{CTC:} \mathrm{arg} \mathrm{CTC} \mathrm{da} \mathrm{argila;} \mathrm{V:} \mathrm{índice} \mathrm{por} \mathrm{saturação} \mathrm{de} \mathrm{bases;} \mathrm{m:} \mathrm{índice} \mathrm{de} \mathrm{saturaçấo}$ por alumínio; P: fósforo assimilável; $\mathrm{C}$ org carbono orgânico total. 
Nos horizontes $\mathrm{A}$, os teores de $\mathrm{Al}^{3+}$ foram baixos, chegando a $1,0 \mathrm{cmol} \mathrm{\textrm {kg } ^ { - 1 }}$ (Tabela 3). Nos horizontes subsuperficiais $\mathrm{B}$ e $\mathrm{C}$, observou-se grande variação, com teores atingindo $15,1 \mathrm{cmol} \mathrm{kg}^{-1}$ (maioria superiores a 4,0 $\mathrm{cmol} \mathrm{kg}^{-1}$ ), tendendo a aumentar em profundidade. Esta variação também foi verificada na saturação por alumínio $(\mathrm{m})$, acompanhando de forma inversa os valores de $\mathrm{V}$ e diminuindo em direçấo ao terço inferior. Padrão diferenciado foi observado em solos do Alto Solimôes por Coelho et al. (2005), com teores significativos de $\mathrm{Al}^{3+}$ em superfície, variando de 1,4 a 9,6 $\mathrm{cmol} \mathrm{kg}^{-1}$ (média de 4,0 $\mathrm{cmol} \mathrm{kg}^{-1}$ de solo) e em subsuperficie entre 0,6 e $8,9 \mathrm{cmol}_{\mathrm{c}} \mathrm{kg}^{-1}$.

Os elevados teores de $\mathrm{Ca}^{2+}, \mathrm{Mg}^{2+} \mathrm{e} \mathrm{Al}^{3+}$ nos horizontes subsuperficiais $(\mathrm{B}$ e $\mathrm{C})$ refletem a presença de argila de alta atividade (CTC argila $\geq 27 \mathrm{cmol}_{\mathrm{c}} \mathrm{kg}^{-1}$ ), exceto no horizonte BA do perfil $\mathrm{P} 1$, com maiores valores nos perfis P2 e P3 (Tabela 3).

Os teores de carbono orgânico $(\mathrm{C}$ org) são mais elevados nos horizontes superficiais $(A)$, com decréscimo brusco nos horizontes transicionais $(\mathrm{AB})$, demonstrando a rápida ciclagem da matéria orgânica na superfície do solo (Tabela 3). Este padrão está relacionado com as elevadas taxas de mineralização da matéria orgânica, em decorrência das condiçốes climáticas da região, ou seja, elevada temperatura, umidade e pluviosidade. Avaliando a distribuição do $\mathrm{C}$ org em solos da Floresta Amazônica, na regiāo do rio Madeira, no Estado do Amazonas, VolKoff e Cerri (1981) verificaram teores elevados somente no horizonte $\mathrm{A}$, com decréscimo significativo nos horizontes $\mathrm{AB}$ e baixos teores nos horizontes subsuperficiais.

A composição química da fração argila de alguns horizontes, determinada a partir do ataque sulfúrico indica teores de $\mathrm{SiO}_{2}$ em maior proporção, entre 250 e $308 \mathrm{~g} \mathrm{~kg}^{-1}$ (Tabela 4). Os teores de $\mathrm{Al}_{2} \mathrm{O}_{3}$ variaram entre $180 \mathrm{e}$ $211 \mathrm{~g} \mathrm{~kg}^{-1}$, sendo maiores em relação aos teores de $\mathrm{Fe}_{2} \mathrm{O}_{3}$ (57 a $70 \mathrm{~g} \mathrm{~kg}^{-1}$ ). Os baixos teores de $\mathrm{Fe}_{2} \mathrm{O}_{3}$ podem ser devido à alta pluviosidade associada à baixa permeabilidade do solo criando condiçóes favoráveis à redução do ferro e, consequentemente, à saída deste sistema (ARAújo et al., 2004).

Os valores das relaçóes moleculares ki e kr foram altos, com valores variando de 2,18 a 2,91 e entre 1,84 e 2,35 respectivamente (Tabela 4). Os valores das relaçôes moleculares sugerem baixo grau de intemperismo dos solos, sendo reflexo da composição mineralógica.

Tabela 4. Elementos obtidos pelo ataque sulfúrico e relaçóes de horizontes selecionados da topossequência estudada no município de Feijó, Estado do Acre

\begin{tabular}{lcccccccc}
\multirow{2}{*}{ Perfil } & Horizonte & $\mathrm{SiO}_{2}$ & $\mathrm{Al}_{2} \mathrm{O}_{3}$ & $\mathrm{Fe}_{2} \mathrm{O}_{3}$ & $\mathrm{TiO}_{2}$ & $\mathbf{k i}$ & $\mathbf{k r}$ \\
\cline { 3 - 6 } & & \multicolumn{7}{c}{$\mathbf{g ~ k g}^{-1}$} \\
P1 & $2 \mathrm{Bt}$ & 278 & 211 & 70 & 5,8 & 2,24 & 1,85 \\
P2 & $\mathrm{Btf1}$ & 278 & 196 & 67 & 4,9 & 2,41 & 1,98 \\
P3 & $\mathrm{Bi}$ & 250 & 195 & 57 & 4,9 & 2,18 & 1,84 \\
& $\mathrm{CV} 2$ & 308 & 180 & 67 & 5,2 & 2,91 & 2,35
\end{tabular}

ki: $\left(\mathrm{SiO}_{2} / \mathrm{Al}_{2} \mathrm{O}_{3}\right) \times 1,7 ; \mathrm{kr}:\left(\mathrm{SiO}_{2} \times 1,7\right) /\left(\mathrm{Al}_{2} \mathrm{O}_{3}+\left(0,64 \times \mathrm{Fe}_{2} \mathrm{O}_{3}\right)\right.$

\section{Atributos Mineralógicos}

A mineralogia das fraçôes areia e silte revelou predomínio de quartzo, seguido pelos feldspatos e plagioclásios (Figuras 2 e 3), indicando que as maiores fraçóes granulométricas dos solos possuem reserva de minerais primários, cuja ação do intemperismo pode liberar nutrientes e alumínio. Destaca-se também a ausência de mica e a presença de illita, identificada pelos reflexos próximos a $10 \AA$. Os dados indicam tendência na diminuição dos feldspatos, plagioclásios e illita do terço inferior para o superior da topossequência. A baixa permeabilidade dos solos atua como impedimento às alteraçóes, possibilitando a ocorrência de minerais facilmente alteráveis nesse pedoambiente. Avaliando a mineralogia de três solos de uma topossequência da Amazônia Ocidental, Lima et al. (2006) verificaram na fraçáo areia quartzo, plagioclásios, micas e feldspatos potássicos, além de calcita no horizonte $\mathrm{C}$ de um Argissolo Amarelo e filossilicatos em um Neossolo Flúvico.

$\mathrm{Na}$ fração argila foram identificados em maior dominância os minerais esmectitas, micas e caulinita, além do quartzo e lepidocrocita, em proporçóes reduzidas e ausentes em algumas amostras (Figuras 4 a 7). Observa-se também a evidência da presença de interestratificado caulinita-esmectita no horizonte $2 \mathrm{Bt}$ do perfil P1.

A mineralogia indica solos ainda náo muito intemperizados, com a presença de minerais $2: 1$ e corroboram a indicação de argila de alta atividade com base nos altos valores de CTC da argila e superfície específica.

A esmectita ocorre de forma bastante expressiva, sendo predominante em quase todos os horizontes analisados, exceto no horizonte $2 \mathrm{Bt}$ do perfil $\mathrm{P} 1$. A presença de esmectita é indicada por sua reflexão principal, na regiáo $6,5^{\circ}(2 \theta)$ de $\sim 1,40$ $\mathrm{nm}$, na amostra saturada com magnésio $(\mathrm{Mg})$, que se desloca

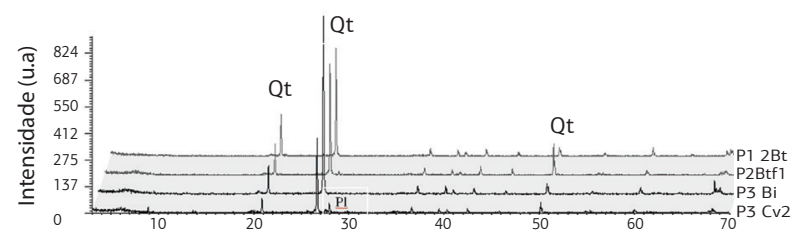

Figura 2. Difratogramas de raio-X da fração areia dos horizontes selecionados da topossequência estudada no município de Feijó, Estado do Acre. Qt: quartzo; Pl: plagioclásio.

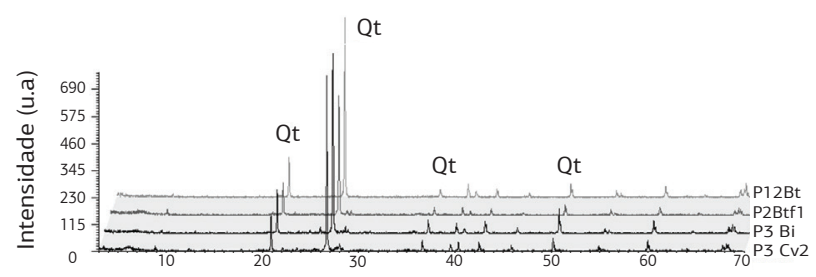

Figura 3. Difratogramas de raio-X da fração silte dos horizontes selecionados da topossequência estudada no município de Feijó, Estado do Acre. Qt: quartzo. 


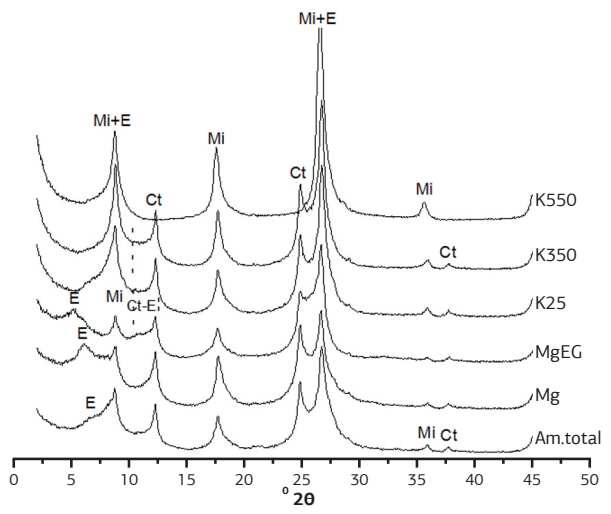

Figura 4. Difratogramas de raio-X da fração argila do horizonte 2Bt (perfil P1) da topossequência estudada no município de Feijó, Estado do Acre. E: esmectita; Mi: mica; Ct-E: interestratificado caulinita-esmectita; Ct: caulinita.

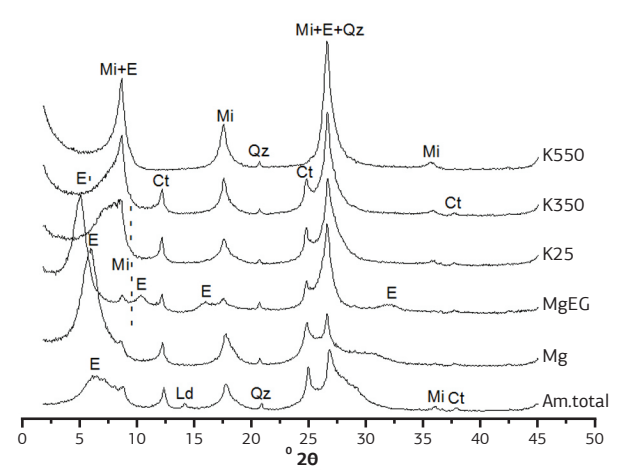

Figura 5. Difratogramas de raio-X da fração argila do horizonte 2Btf1 (perfil P2) da topossequência estudada no município de Feijó, Estado do Acre. E: esmectita; Mi: mica; Ct: caulinita; Ld: lepidocrocita; Qz: quartzo.

(indicando expansão) após o tratamento com etileno glicol (MgEG), com destaque a intensidade e a forma desta reflexão nos difratogramas da amostra Mg-saturada (Figura 4).

A mica (termo inclusivo para illita) ocorre em todos os horizontes analisados, como indicam as reflexóes diagnósticas a $\sim 8,85^{\circ}, 17,65^{\circ}$ e $26,70^{\circ}(2 \theta)$, que permanecem estáveis aos tratamentos aplicados. $\mathrm{O}$ aumento de intensidade, observado após aquecimento a 350 e $550^{\circ} \mathrm{C}$ se deve ao colapso dos outros argilominerais $2: 1$ presentes. Sua ocorrência é bastante expressiva em todos os horizontes com aparente predominância sobre a caulinita. A caulinita também ocorre em todos os horizontes analisados e, em proporçôes inferiores aos anteriores. Sua presença evidencia-se pelas reflexóes bem formadas, as quais ocorrem na regiáo de $12,3^{\circ}, 24,8^{\circ}$ e $37,7^{\circ}(2 \theta)$ e que desaparecem após o aquecimento da amostra a $550^{\circ} \mathrm{C}$ (K 550).

No horizonte $2 \mathrm{Bt}$ do perfil $\mathrm{P} 1$ verifica-se a presença de interestratificado caulinita-esmectita, evidenciada por um reflexo ao lado das reflexóes da caulinita na amostra saturada com magnésio após o tratamento com etileno glicol

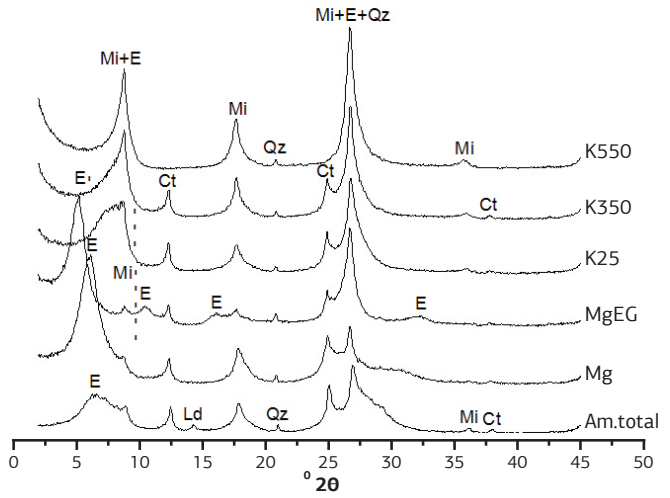

Figura 6. Difratogramas de raio-X da fração argila do horizonte Bi (perfil P3) da topossequência estudada no município de Feijó, Estado do Acre. E: esmectita; Mi: mica; Ct: caulinita; Ld: lepidocrocita; Qz: quartzo.

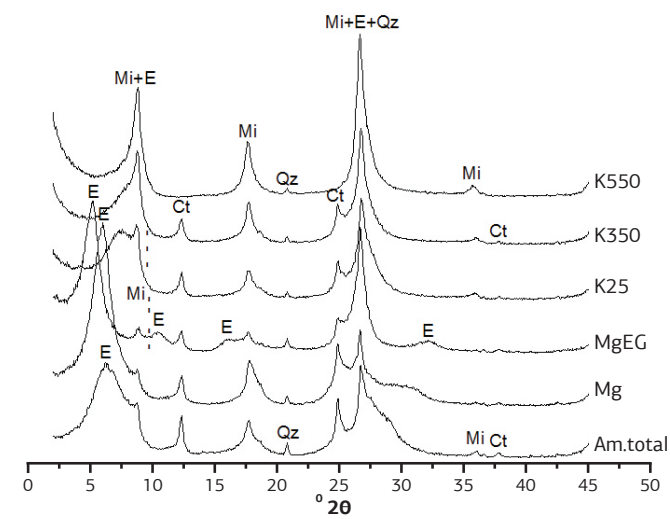

Figura 7. Difratogramas de raio-X da fração argila do horizonte Cv2 (perfil P3) da topossequência estudada no município de Feijó, Estado do Acre. E: esmectita; Mi: mica; Ct: caulinita; Qz: quartzo.

$(\mathrm{MgEG})$ e melhor visualizada junto à reflexão a $12,3^{\circ}(2 \theta)$ (Figura 4). Não deve ser confundida com a segunda reflexão da esmectita que também ocorre nesta região, porém de forma individualizada, como se observa nas outras amostras. A presença do interestratificado esmectita sugere que esta foi parcialmente transformada durante diagênese.

Observa-se também em algumas amostras a presença de lepidocrocita, cuja reflexão é perceptível apenas na amostra não tratada, desaparecendo após o tratamento de desferrificação, e ainda a presença de quartzo, ambos em proporçóes reduzidas.

Em estudo com solos de Rio Branco e Manuel Urbano, no Acre, Volkoff et al. (1989) observaram que minerais como as esmectitas são predominantes em horizontes incipientes e mais profundos, sendo características da classe dos Cambissolos, e predomínio de illita nos horizontes mais desenvolvidos, em solos da classes dos Argissolos, sendo este padrão, nos Argissolos, decorrente da degradação das esmectitas e reflexo no maior grau de desenvolvimento pedogenético. 
Avaliando de forma comparativa os difratogramas dos horizontes selecionados, os perfis P1 e P2 podem ser agrupados como 'esmectíticos', e o perfil P3 como de 'constituição mista', onde se tem a aparente equivalência de proporçôes, porém com predominância dos argilominerais 2:1 (Esmectita+Mica>Caulinita).

\section{Classificação dos solos}

A geologia recente da Formação Solimôes, composta principalmente por sedimentos, proporcionou um pequeno tempo para a exposição do material de origem à ação dos agentes intempéricos mesmo em clima quente e úmido, direcionando a formação de solos com baixo grau de desenvolvimento pedogenético. Tal fato pode ser constatado ao analisar a alta atividade da fração argila, mineralogia da fração argila e areia com minerais 2:1 e primários, altos valores de ki e da relação silte/argila, indicando que os solos ainda preservam características do material de origem sedimentar (Frailey et al., 1998).

$\mathrm{O}$ ambiente de alteração desses solos, caracterizado pela manutenção de sílica e bases favorece a ocorrência de argilominerais do tipo 2:1, a partir da combinação de adiçóes sedimentares e precipitação da solução (Marques et al., 2002). Aliado ao exposto, a presença de argilas de alta atividade contribuem para a redução da condutividade hidráulica e manutenção de água por maior período de tempo, favorecendo as reaçóes de oxidação/redução, com a segregação do ferro, propiciando a formação dos mosqueados, embora haja também a ocorrência de plintita.

Quanto à classificação taxonômica, todos os horizontes superficiais foram classificados como A moderado e os horizontes subsuperficiais como B textural (perfis P1 e P2) e B incipiente (perfil P3) segundo o Sistema Brasileiro de Classificação de Solos (EMBRAPA, 2006).

No perfil P1, o gradiente textural igual a 2,4 indica o acúmulo de argila nos horizontes subsuperficiais, classificando o horizonte B textural e indicando ordem dos Argissolos. Pela expressáo das cores com matiz 2,5YR na maior parte dos primeiros $100 \mathrm{~cm}$ do horizonte B foi classificado na subordem Vermelho e a presença de caráter alítico atribuiu ao perfil à classificação como Alítico no nível de grande grupo. A presença de cores de redução e mosqueados proeminentes no horizonte $2 \mathrm{Btf}$ dentro de $150 \mathrm{~cm}$ de profundidade sugere o nível de subgrupo plíntico.

O perfil P2 com gradiente textural igual a 1,7 e horizontes subsuperficiais com cores acinzentadas, matiz $10 \mathrm{YR}$ e croma $\leq 3$ leva à classificação na ordem dos Argissolos e subordem Acinzentado. Para o nível de grande grupo como Distrófico e a presença de cores de reduçâo e mosqueados proeminentes no horizonte Btf1 e
Btf2 dentro de $150 \mathrm{~cm}$ de profundidade sugere o nível de subgrupo plíntico.

O perfil 3 apresentou horizonte subsuperficial com baixo desenvolvimento pedológico, sendo classificado como horizonte B incipiente. A presença de horizonte Bi e ausência de atributos diagnósticos faz com que o perfil seja classificado no nível de ordem como Cambissolos e em subordem como Háplico. Apesar dos altos teores de $\mathrm{Al}^{+}$no horizonte $\mathrm{Bi}$, os valores de $\mathrm{V}$ foram maiores que $50 \%$, levando à classificação de Eutrófico no nível de grande grupo e para o nível de subgrupo típico.

\section{CONCLUSÃO}

Os solos possuem baixo grau de desenvolvimento pedogenético, com minerais da fração argila de alta atividade e predominância de esmectitas, illitas e interestratificados de caulinita-esmectita, além da presença de quantidades significativas de minerais primários, como feldspato e plagioclásio, nas fraçôes areia e silte.

Os solos foram classificados segundo o Sistema Brasileiro de Classificação de Solos vigente como Argissolo Vermelho Álitico plíntico (P1), Argissolo Acinzentado Distrófico plíntico (P2) e Cambissolo Háplico Ta Eutrófico típico (P3).

\section{REFERÊNCIAS}

ACRE. Governo do Estado do Acre. Programa Estadual de Zoneamento Ecológico Econômico do Estado do Acre. Zoneamento Ecológico-Econômico - ZEE/AC 2a fase. Rio Branco: SECTMA, 2006. (CD-ROM)

ARAÚJO, E.A.; LANI, J.L.; AMARAL, E.F.; GUERRA, A. Uso da terra e propriedades físicas e químicas de Argissolo Amarelo distrófico na Amazônia Ocidental. Revista Brasileira de Ciência do Solo, v.28, p.307-315, 2004.

BRANCO, P.M. Dicionário de Mineralogia. 3.ed. Porto Alegre: Sagra, 1987. 362p.

BRINDLEY, G.W.; BROWN, G. Crystal structures of clay minerals and their X-ray identification. London: Mineralogical Society, 1984. 495p.

BRASIL. Ministério das Minas e Energias. Departamento Nacional da Produção Mineral. Projeto RADAMBRASIL - Levantamento de recursos naturais. Folhas SC. 19 Rio Branco: geologia, geomorfologia, pedologia, vegetação, uso potencial da terra. Rio de Janeiro: Divisão de Publicação, 1976. 12 v. 464p.

CALDERANO, S.B.; DUARTE, M.N.; GREGORIS, G. Análise mineralógica das fraçóes finas do solo por difratometria de raios-X: revisão e atualização da metodologia e critérios usados na Embrapa Solos. Rio de Janeiro: Embrapa Solos, 2009. (Embrapa Solos, Comunicado Técnico, 53) 
CARTER, D.L.; HEILMAN M.D.; GONZALES, C.L. Ethylene glycol monoethyl ether for determining surface area of silicate minerals. Soil Science, v.100, p.356-360, 1965.

CAVALCANTE, L.M. Relatório sobre a Geologia do Estado do Acre. Rio Branco: SEMA/IMAC, 2006. (Texto integrante do eixo recursos naturais do ZEE Fase II).

CIHACEK, L.J.; BREMNER, J.M. A simplified ethylene glycol monoethyl ether procedure for assessement of soil surface area. Soil Science Society of America Journal, v.43, p.821-822, 1979.

COELHO, M.R.; FIDALGO, E.C.C.; ARAÚJO, F.O.; SANTOS, H.G.; SANTOS, M.L.M.; PÉREZ, D.V.; MOREIRA, F.M.S. Levantamento Pedológico de uma Área-Piloto Relacionada ao Projeto BiosBrasil (Conservation and Sustainable Management of Below-Ground Biodiversity: Phase I), Município de Benjamin Constant (AM): Janela 6. Embrapa: Rio de Janeiro, 2005. 95p. (Boletim de Pesquisa e Desenvolvimento, 68)

DAY, P.R. Particle fractionation and particle size analysis. In: BLACK, C.A. (Ed.). Methods of soil analysis: Physical and mineralogical properties, including statistics of measurement and sampling. Madison: American Society of Agronomy, 1965. p.545-567.

EMBRAPA. Centro Nacional de Pesquisa de Solos (Rio de Janeiro, RJ). Manual de métodos de análises de solo. Rio de Janeiro, 1997. 212p.

EMBRAPA. Sistema Brasileiro de Classificação de Solos. 2.ed. Brasília: Embrapa Produção de Informação; Rio de Janeiro: Embrapa Solos, 2006. 312p.

FRAILEY, C.D.; LAVINA, E.L.; RANCY, A. SOUZA FILHO, J.P. A proposed Pleistocene/Holocene lake in the Amazon basin and its significance to amazonian geology and biogegraphy. Acta Amazônica, v.18, p.119-143, 1998.

HEILMAN, M.D.; CARTER, D.L; GONZALEZ, C.L. The ethylene glycol monethyl ether (EGME) technique for determining soil surface area. Soil Science, v.100, p.409-413, 1965.

LIMA, H.N.; MELLO, J.W.V.; SCHAEFER, C.E.G.R.; KER, J.C.; LIMA, A.M.N. Mineralogia e química de três solos de uma toposseqüência da bacia sedimentar do Alto Solimôes, Amazônia ocidental. Revista Brasileira de Ciência do Solo, v.30, p.59-68, 2006.
MARQUES, J.J.; TEIXEIRA, W.G.; SCHULZE, D.G.; CURI, N. Mineralogy of soils with unusually high exchangeable Al from the western Amazon Region. Clay Minerals, v.37, p.651-661, 2002.

MERHA, O.P.; JACKSON, M.L. Iron oxide removal From SOILS AND CLAYS BY A DITHIONITE-CITRATE SYSTEM BUFFERED WITH SODIUM BICARBONATE. IN: NATIONAL CONFERENCE ON CLAYS AND CLAY MINERALS, 7, WASHINGTON, DC, I958. Proceedings... New York: Pergamon Press, i 960. P.3 I7-327.

MOORE, D.M.; REINOLDS JR., R.C. X-ray diffraction and the identification and analysis of clay minerals. 2.ed. Oxford: Oxford University Press, 1997. 378p.

SANTOS, R.D.; LEMOS, R.C.; SANTOS, H.G.; KER, J.C.; ANJOS, L.H.C. Manual de descrição e coleta de solo no campo. 5.ed. Revista e ampliada, Viçosa: Sociedade Brasileira de Ciência do Solo/ Embrapa Solos, 2005. 100p.

PVOLKOFF, B.; CERRI, C.C. Húmus em solos da floresta Amazônica na regiáo do rio Madeira. Revista Brasileira da Ciência do Solo, v.5, p.15-21, 1981.

THOREZ, J. Practical identification of clay minerals. Liege: Liege State University, 1976. 1 v. 90p.

VOLKOFF, B.; CERRI, C.C. Húmus em solos da floresta Amazônica na região do rio Madeira. Revista Brasileira da Ciência do Solo, v.5, p.15-21, 1981.

VOLKOFF, B.; MELFI, A.J.; CERRI, C.C. Solos Podzólicos e Cambissólicos Eutróficos do Alto Purus (Estado do Acre). Revista Brasileira de Ciência do Solo, v.13, p.363-372, 1989.

WADT, P.G.S. Manejo dos Solos Ácidos do Estado do Acre. Rio Branco: Embrapa Acre, 2002. 28p. (Embrapa Acre. Documentos, 79)

WADT, P.G.S. Estoque de carbono em um Plintossolo Argilúvico da Formaçáo Solimões, Amazônia, Brasil. Rio Branco: Embrapa Acre, 2004. 22p. (Embrapa Acre. Boletim de Pesquisa e Desenvolvimento, 41)

WESTAWAY, R. Late Cenozoic sedimentary sequences in Acre state, southwestern Amazonia: Fluvial or tidal? Deductions from the IGCP 449 fieldtrip Rob Westaway. Journal of South American Earth Sciences, v.21, p.120-134, 2006. 